\title{
Utilization and Outcome of 'Out-of-Center Hemodialysis' in the United States: A Contemporary Analysis
}

\author{
Jennifer M. MacRae ${ }^{a}$ Caren L. Rose ${ }^{b}$ Bertrand L. Jaber ${ }^{b}$ John S. Gill ${ }^{c}$ \\ aDivision of Nephrology, University of Calgary, Calgary, Alta., and ${ }^{b}$ Division of Nephrology, \\ University of British Columbia, Vancouver, B.C., Canada; ' ${ }^{C}$ Division of Nephrology, St. Elizabeth's Medical Center, \\ Tufts University School of Medicine, Boston, Mass., USA
}

\section{Key Words}

Home setting • Out-of-center hemodialysis • Hemodialysis •

Peritoneal dialysis $\cdot$ Long-term care facility $\cdot$ Survival

\begin{abstract}
Background: There is increasing interest in the delivery of out-of-center hemodialysis (HD), particularly in the home setting, but little systematic information about its use and outcome in contemporary incident patients is available. Patients and Methods: Out-of-center HD was defined as HD delivered in a residential setting, mainly at home or in a longterm care facility (such as a nursing home) irrespective of the length and frequency of therapy. All-cause mortality was determined in an observational cohort study of 458,329 adult patients initiating dialysis in the United States with Medicare as a primary payer. Results: Between 1995 and 2004, out-ofcenter HD was the initial modality in 1,641 (0.4\%) of eligible participants, although there was significant geographic variation. Patients initiating out-of-center HD were younger, more likely to be nonwhite, had fewer comorbidities, a higher median income, and were more likely to be employed than patients initiating in-center HD or peritoneal dialysis (PD). In multivariate analysis, out-of-center HD patients had a higher overall risk of death compared to in-center HD or
\end{abstract}

PD patients ( $\mathrm{HR}=1.10,95 \% \mathrm{Cl} 1.04,1.17)$, although the relative risk of death was lower in younger and healthier patients ( $\mathrm{HR}=0.78 ; 95 \% \mathrm{Cl} 0.61,1.00)$. Conclusion: Out-of-center HD is not associated with a survival advantage among unselected patients initiating dialysis in the United States. These results call for better characterization of out-of-center HD in national registries, primarily to effectively compare the use, outcomes and potential benefits of home HD to standard therapies.

Copyright $\odot 2010$ S. Karger AG, Basel

\section{Introduction}

Home hemodialysis (HD) was first introduced in 1964 [1], and its use in the United States peaked in the 1970s [2] when $40 \%$ of prevalent patients with end-stage renal disease (ESRD) were treated at home [3]. Unfortunately, the utilization of home HD subsequently declined due to re-

B.L.J. is a member of the Scientific Advisory Board of NxStage Medical, Inc. (Lawrence, Mass., USA)., and serves as principal advisor to the FREEDOM Study, a cohort study of daily HD that is sponsored and funded by NxStage Medical, Inc.

\section{KARGER}

๑ 2010 S. Karger AG, Basel

Fax +41613061234

E-Mail karger@karger.ch

www.karger.com
Accessible online at:

www.karger.com/nec
Jennifer MacRae, MD

1403 29th Street NW

Calgary, AB T2P 2T9 (Canada)

Tel. +1 403944 8168, Fax +1 4039442876

E-Mail jennifer.macrae@albertahealthservices.ca 
imbursement issues, complicated HD technology, lack of home HD expertise and training programs, and the concept that adequate dialysis could be achieved with conventional HD [4-6]. Home HD has attracted increasing attention in recent years, perhaps driven by declining expertise in peritoneal dialysis (PD) [7], advances in home HD technologies [8], and patient preferences for modalities with greater flexibility in the scheduling of dialysis treatments.

Home HD has been linked to improved outcomes [912] including better patient survival $[3,5,10,13]$ lower costs $[15,16]$, and enhanced quality of life [17]. However, much of this information is derived from small studies published in the late 1980s or early 1990s and may not reflect contemporary practice. A more recent observational study revealed significantly better patient survival in 265 patients receiving short daily home HD as compared to United States Renal Data System (USRDS)matched patients receiving conventional in-center HD [5]. Frequent home HD has also been demonstrated, in a randomized controlled trial [18], to improve blood pressure control and reduce left ventricular mass. A systematic review that included 27 studies of variable quality found that home HD was associated with improved survival and quality of life [16]; however, concerns with selection bias led to the conclusion that it was difficult to 'disentangle the true effects of home HD'. We therefore performed this study to determine the use and outcome of home HD in a contemporary patient population initiating dialysis in the United States. Due to the nonexistence of home HD registries, we resorted to an operational definition of out-of-center HD, as defined by the USRDS, which entailed delivery of HD in a residential setting either at home or in a long-term care facility.

\section{Patients and Methods}

\section{Data Sources}

The study population was drawn from the Standard Analysis Files of the USRDS, and included all adult patients aged $\geq 18$ years who initiated chronic dialysis between April 1, 1995 and October 31,2004 . The medical evidence file includes information from the Medical Evidence Form of the Center for Medicare and Medicaid Services, which is completed for all incident ESRD patients [19]. We studied the subset of patients whose primary insurer was Medicare or Medicaid in order to ensure complete identification of treatment modality and change in treatment modality for Medicare claims. Included patients were required to be stable on a single dialysis modality for a minimum of 60 days [19]. Patients with kidney transplantation as their initial treatment modality or patients whose initial modality could not be identified were excluded. Dialysis modality and location (residential vs. in-center) were determined from the Detailed Treatment History file. The determination of dialysis modality switches followed the 60-day rule used by the USRDS whereby any change in modality lasting less than 60 days is not recorded as a modality switch [19]. The study was approved by our local hospital institutional review board.

Dialysis Modality Definitions and Patient Follow-Up

Modalities of first dialysis were classified as: (1) out-of-center $\mathrm{HD}$, defined as HD delivered in a residential setting (including home and long-term care facilities such as nursing homes) irrespective of the length and frequency of therapy; (2) in-center HD, defined as staff-assisted or self-care HD delivered in a dialysis facility which includes both hospital and satellite units; and (3) PD, defined as chronic ambulatory PD (CAPD), continuous cycler PD (CCPD), or other PD modality delivered in the residential setting. Patients were followed from the initiation of dialysis until transplantation, death, or December 31, 2004, which was the last day of study follow-up.

\section{Statistical Analysis}

All analyses were performed with SAS version 9.1 (Cary, N.C., USA). Differences in demographic and clinical characteristics between included and excluded patients, and between study patients initiating out-of-center $\mathrm{HD}$, in-center $\mathrm{HD}$ and PD were compared using the $\chi^{2}$ test, $\mathrm{t}$ test or ANOVA as appropriate.

The rate of out-of-center HD use among incident dialysis patients was determined in each of the 18 ESRD networks using Poisson regression. Rates were calculated per 1,000 patient years on dialysis. Under the direction of the Center for Medicare and Medicaid Services, the ESRD Network Program consists of a national network of 18 ESRD networks, responsible for each US state, territory, and the District of Columbia. ESRD networks service geographic areas based on the number and concentration of ESRD beneficiaries.

Univariate and multivariate logistic regression analyses were performed to identify factors associated with the use of out-ofcenter HD in incident dialysis patients compared to the other dialysis modalities. The following variables were examined: age; gender; race; cause of ESRD; diabetes; cardiovascular disease (CVD) [as defined by a history of ischemic heart disease (IHD), congestive heart failure (CHF), cerebrovascular accident, or peripheral vascular disease]; self-reported functional status (in terms of ability to transfer and ambulate independently); era in which dialysis was initiated (1995-1997, 1998-2000, 2001-2004); median household income (determined by linkage of patient zip codes to data from the 2002 US Census), and employment status.

\section{Patient Survival Analysis}

The association of initial treatment modality with patient survival was determined in univariate (Kaplan-Meier) and multivariate (Cox regression) intention-to-treat analyses. The Cox regression analyses included adjustment for the following factors: age, gender, race, cause of ESRD, diabetes, history of CVD, self-reported functional status, era in which dialysis was initiated, median household income, and employment status. Covariates in the model were tested for the proportionality assumption using lognegative-log plots plotted against the log of time. This analysis was repeated while censoring follow-up at the time of change in treatment modality. 
Patient Survival in Subgroups

Because the 'residential setting' used to define out-of-center HD includes home and long-term care facilities mainly nursing homes, we defined a subgroup of patients who were more likely to reside at home than in a long-term care facility (aged $<50$ years, able to ambulate and transfer independently, and absence of diabetes and CVD). We also defined a subgroup of patients who were more likely to reside in a long-term care facility than at home (aged $>60$ years, inability to ambulate and transfer independently, and presence of at least diabetes and/or CVD). The association of out-of-center HD with survival was determined in these subgroups using the same aforementioned methods.

\section{Propensity Score Analysis}

Because treatment assignment was nonrandom, we attempted to control for factors associated with initiating out-of-center HD by developing a propensity score. The propensity score was developed by creating a logistic regression model to ascertain the factors that were associated with out-of-center HD. An optimal model was created by forcing all variables into the model. A propensity score was then assigned to each patient by multiplying their characteristics by the model coefficients and adding over these characteristics to obtain a likelihood of out-of-center HD. The score ranged between 0 and 1 . Each out-of-center HD patient was matched by a ratio of 1:3 to randomly selected in-center HD patients with the same propensity score. Patient survival analyses were then repeated in this matched cohort of patients.

\section{Results}

\section{Characteristics of Patients Initiating Out-of-Center $H D$ in the US}

Among the 744,047 patients who initiated chronic dialysis treatment in the US during the study period, 251,675 were excluded, as Medicare/Medicaid was not their primary insurance payer, and a further 34,043 were excluded due to a lack of a stable dialysis modality for 60 days, leaving 458,329 study patients. Study patients were older ( $65 \pm 15$ vs. $58 \pm 15$ years, $\mathrm{p}<0.0001)$, less likely to be male ( 53 vs. $56 \%, \mathrm{p}<0.0001$ ), and more likely to be white ( 65 vs. $63 \%, \mathrm{p}<0.0001)$, have diabetes as the cause of ESRD (46 vs. $44 \%, \mathrm{p}<0.0001$ ), and have a preexisting history of IHD (27 vs. $20 \%$, p < 0.0001), CHF (36 vs. $27 \%$, $\mathrm{p}<0.0001$ ), cerebrovascular accident (10 vs. 7\%, p < 0.0001 ), and peripheral vascular disease (16 vs. $12 \%, \mathrm{p}<$ $0.0001)$ than those who were excluded.

Table 1 depicts the baseline characteristics of patients initiating out-of-center $\mathrm{HD}$, in-center $\mathrm{HD}$ and $\mathrm{PD}$ during the study period; only 1,641 (0.4\%) initiated out-of-center HD. Patients initiating out-of-center HD were younger, more likely to be nonwhite and had fewer comorbid conditions, but had a lower functional status as suggested by an inability to ambulate or transfer independently. Out-

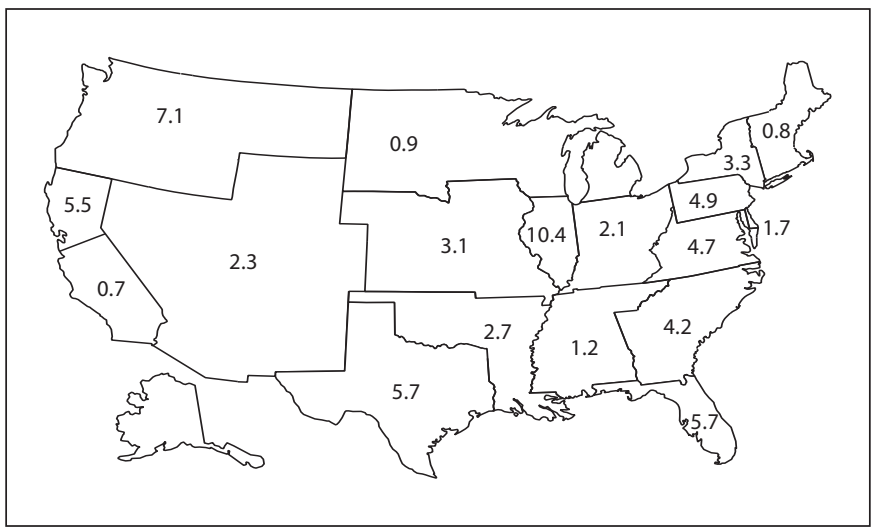

Fig. 1. Map of out-of-center HD rate (per 1,000 incident patients with ESRD initiating dialysis) in the US between 1995 and 2004 stratified by USRDS network.

of-center HD patients also had a higher median income, and were more likely to be employed compared to patients initiating in-center HD or PD.

Figure 1 demonstrates the geographic variation of the incident patient population initiating out-of-center HD across the 18 US networks. Network 9 (TriState Renal Network), had the highest incidence rate of out-of-center HD (10.4 out-of-center HD patients/1,000 patients initiating dialysis), followed by Network 16 (Northwest Renal Network, 7.1 out-of-center HD patients/1,000 patients initiating dialysis), with Networks 7 (Florida), 14 (Texas) and 17 (Trans-Pacific Network) having the next highest utilization of out-of-center HD (5.7, 5.7 and 5.5 out-ofcenter HD patients/1,000 patients initiating dialysis, respectively).

\section{Patient Survival}

In univariate analysis, patient survival was similar among patients who initiated out-of-center HD, in-center HD, and PD (fig. 2). In multivariate analysis, patients who initiated out-of-center HD had a significantly higher relative risk of death compared to patients starting treatment with other dialysis modalities [hazard ratio $(\mathrm{HR})=1.10$; 95\% confidence interval (CI) 1.04, 1.17; table 2]. In additional multivariate analyses, patients initiating out-of-center $\mathrm{HD}$ had a higher relative risk of death compared to patients initiating in-center HD ( $\mathrm{HR}=1.10 ; 95 \%$ CI 1.04, 1.17; $\mathrm{p}=0.002)$, but had similar relative risk of death compared to $\mathrm{PD}$ patients $(\mathrm{HR}=$ 1.04; 95\% CI 0.98, 1.11; $\mathrm{p}=0.20$ ). Similar results were obtained when patient follow-up was censored at the 
Table 1. Characteristics of incident dialysis patients stratified by initial dialysis modality

\begin{tabular}{|c|c|c|c|c|}
\hline & $\begin{array}{l}P D \\
(n=37,253)\end{array}$ & $\begin{array}{l}\text { In-center HD } \\
(\mathrm{n}=419,435)\end{array}$ & $\begin{array}{l}\text { Out-of-center HD } \\
(\mathrm{n}=1,641)\end{array}$ & $\mathrm{p}$ value \\
\hline \multicolumn{5}{|l|}{ Age category, \% } \\
\hline $18-44$ & 18.4 & 11.4 & 16.1 & \multirow[t]{4}{*}{$<0.0001$} \\
\hline $45-59$ & 23.9 & 19.7 & 24.1 & \\
\hline $60-74$ & 40.4 & 40.2 & 32.8 & \\
\hline$\geq 75$ & 17.3 & 28.7 & 27.0 & \\
\hline Male, $\%$ & 52.8 & 52.4 & 54.4 & 0.11 \\
\hline \multicolumn{5}{|l|}{ Race, \% } \\
\hline White & 73.6 & 63.4 & 60.8 & \multirow[t]{5}{*}{$<0.0001$} \\
\hline Black & 20.5 & 31.2 & 32.8 & \\
\hline Asian & 3.2 & 3.0 & 4.1 & \\
\hline Native American & 1.3 & 1.3 & 1.6 & \\
\hline Other & 1.3 & 1.1 & 0.7 & \\
\hline \multicolumn{5}{|l|}{ Cause of ESRD, $\%$} \\
\hline Diabetes mellitus & 47.0 & 46.0 & 41.7 & \multirow[t]{3}{*}{$<0.0001$} \\
\hline Glomerulonephritis & 14.6 & 9.3 & 11.5 & \\
\hline Other & 38.4 & 44.7 & 46.8 & \\
\hline \multicolumn{5}{|l|}{ Comorbid conditions, $\%$} \\
\hline IHD & 23.0 & 26.7 & 17.6 & $<0.0001$ \\
\hline $\mathrm{CHF}$ & 26.3 & 35.6 & 26.5 & $<0.0001$ \\
\hline CVA & 7.8 & 10.3 & 9.6 & $<0.0001$ \\
\hline PVD & 13.2 & 16.0 & 12.3 & $<0.0001$ \\
\hline \multicolumn{5}{|c|}{ Self-reported functional status, \% } \\
\hline Inability to ambulate & 1.9 & 4.6 & 7.3 & $<0.0001$ \\
\hline Inability to transfer & 0.5 & 1.6 & 3.8 & $<0.0001$ \\
\hline \multicolumn{5}{|l|}{ Median income, $\%$} \\
\hline$<29,000$ USD & 20.9 & 24.5 & 19.2 & \multirow[t]{4}{*}{$<0.0001$} \\
\hline 29,000-35,999 USD & 24.7 & 24.6 & 21.3 & \\
\hline $36,000-45,999$ USD & 26.6 & 25.7 & 25.8 & \\
\hline$\geq 46,000$ USD & 27.8 & 25.0 & 33.7 & \\
\hline \multicolumn{5}{|l|}{ Employment status, $\%^{1}$} \\
\hline Employed & 51.4 & 51.4 & 55.1 & \multirow[t]{4}{*}{$<0.0001$} \\
\hline Retired & 23.2 & 22.0 & 21.0 & \\
\hline Unemployed & 18.9 & 20.9 & 19.3 & \\
\hline Homemaker & 6.5 & 5.7 & 4.6 & \\
\hline
\end{tabular}

CVA = Cerebrovascular accident PVD = peripheral vascular disease.

${ }^{1}$ Employment status could be determined for $95.2 \%$ of patients.

time of treatment modality change (HR for out-of-center HD compared with other treatment modalities 1.38 , 95\% CI 1.26, 1.52).

Subgroup analyses were performed to determine if the relationship between modality and survival differed in patients who were more likely to reside at home (i.e. patients aged $<50$ years, able to ambulate and transfer independently, and absence of diabetes and CVD) and those who were more likely to reside in a long-term care facility (i.e. patients aged $>60$ years with inability to ambulate and transfer independently, and presence of at least dia- betes and/or CVD). Indeed, among those more likely to reside at home, the use of out-of-center HD as the initial treatment modality was associated with a significantly lower relative risk of death compared to other dialysis modalities ( $\mathrm{HR}=0.78 ; 95 \%$ CI 0.61, 1.00; $\mathrm{p}=0.05)$. In contrast, among those more likely to reside in long-term care facilities, out-of center HD was not associated with a significantly different relative risk of death compared to other dialysis modalities $(\mathrm{HR}=1.13,95 \%$ CI $0.90,1.42$; $\mathrm{p}=0.28$ ). 
Table 2. Multivariate analysis of patient survival among incident dialysis patients

\begin{tabular}{|c|c|c|}
\hline & Hazard ratio & $95 \% \mathrm{CI}$ \\
\hline \multicolumn{3}{|l|}{ Modality } \\
\hline $\begin{array}{l}\text { Out-of-center HD } \\
\text { (vs. other modalities) }\end{array}$ & 1.10 & $1.04,1.17$ \\
\hline $\begin{array}{l}\text { Out-of-center HD } \\
\text { (vs. in-center HD) }\end{array}$ & 1.10 & $1.04,1.17$ \\
\hline $\begin{array}{l}\text { Out-of-center HD } \\
\text { (vs. peritoneal dialysis) }\end{array}$ & 1.04 & $0.98,1.11$ \\
\hline \multicolumn{3}{|l|}{ Age category } \\
\hline $18-44$ & 0.44 & $0.43,0.45$ \\
\hline $45-59$ & 0.65 & $0.64,0.65$ \\
\hline $60-74$ & 1.00 & - \\
\hline$\geq 75$ & 1.58 & $1.56,1.59$ \\
\hline Women (vs. men) & 0.99 & $0.98,1.00$ \\
\hline \multicolumn{3}{|l|}{ Race } \\
\hline White & 1.00 & - \\
\hline Black & 0.77 & $0.76,0.78$ \\
\hline Asian & 0.68 & $0.67,0.70$ \\
\hline Native American & 0.71 & $0.69,0.74$ \\
\hline Other & 0.97 & $0.93,1.00$ \\
\hline \multicolumn{3}{|l|}{ Cause of ESRD } \\
\hline Glomerulonephritis & 1.00 & - \\
\hline Diabetes mellitus & 1.38 & $1.35,1.40$ \\
\hline Other & 1.26 & $1.24,1.28$ \\
\hline \multicolumn{3}{|l|}{ Comorbid conditions } \\
\hline IHD (vs. none) & 1.09 & $1.08,1.10$ \\
\hline CHF (vs. none) & 1.27 & $1.25,1.28$ \\
\hline PVD (vs. none) & 1.15 & $1.14,1.17$ \\
\hline CVA (vs. none) & 1.18 & $1.17,1.20$ \\
\hline \multicolumn{3}{|c|}{ Self-reported functional status } \\
\hline Inability to ambulate & 1.46 & $1.43,1.49$ \\
\hline Inability to transfer & 1.32 & $1.28,1.37$ \\
\hline \multicolumn{3}{|l|}{ Median income } \\
\hline$<29,000$ USD & 1.00 & - \\
\hline 29,000-35,999 USD & 0.98 & $0.97,0.99$ \\
\hline $36,000-45,999$ USD & 0.96 & $0.95,0.97$ \\
\hline$\geq 46,000$ USD & 0.94 & $0.93,0.95$ \\
\hline \multicolumn{3}{|l|}{ Employment status } \\
\hline Employed & 1.00 & - \\
\hline Homemaker & 0.93 & $0.91,0.94$ \\
\hline Retired & 1.06 & $1.05,1.07$ \\
\hline Unemployed & 1.00 & $0.99,1.02$ \\
\hline Other/unknown & 1.03 & $1.02,1.05$ \\
\hline \multicolumn{3}{|l|}{ Dialysis initiation period } \\
\hline $1995-1997$ & 1.00 & - \\
\hline 1998-2000 & 0.97 & $0.96,0.98$ \\
\hline 2001-2004 & 0.92 & $0.91,0.93$ \\
\hline
\end{tabular}

Intention-to-treat analysis based on first dialysis modality. PVD = Peripheral vascular disease CVA = cerebrovascular accident.

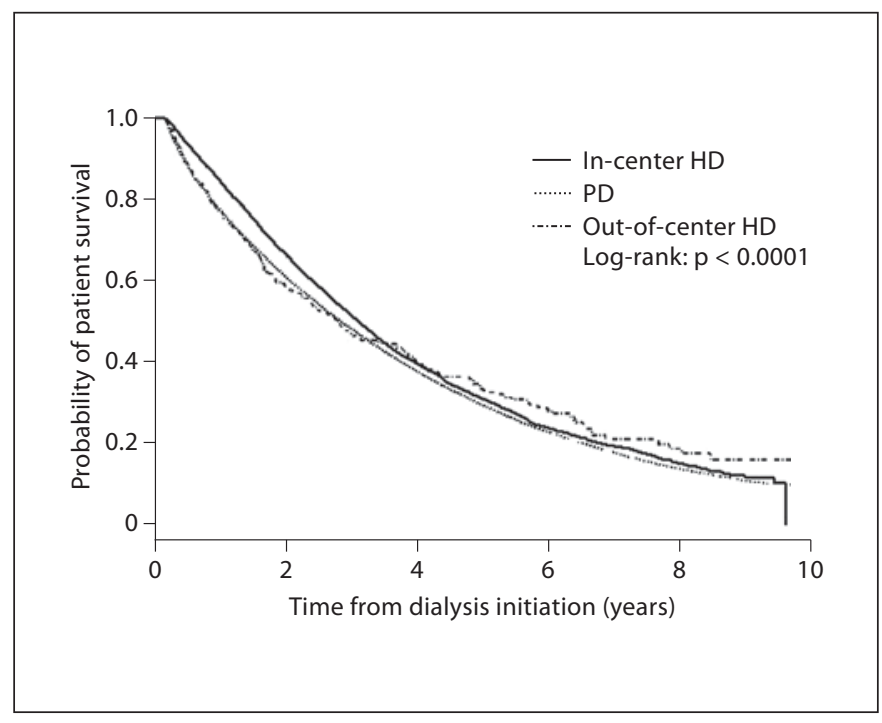

Fig. 2. Cumulative probability of patient survival stratified by initial dialysis modality.

\section{Sensitivity Analysis}

In a sensitivity analysis where out-of-center HD patients were matched to in-center HD patients by their propensity score for starting out-of-center HD, we did not find any association between modality and improved survival (data not shown). We also performed a separate analysis where we matched patients initiating home HD to PD on a propensity score using age and comorbidities. In this sensitivity analysis, patients initiating out-of-center HD maintained a higher relative risk of death compared to those initiating $\mathrm{PD}(\mathrm{HR}=1.11$; 95\% CI 1.03, 1.19).

\section{Discussion}

\section{Major Study Findings}

In the present study, we attempted to examine the use and outcome of HD delivered in residential settings, in a contemporary patient population initiating dialysis in the US. Due to the lack of true home HD registries, we resorted to an operational definition of out-of-center HD, as defined by the USRDS, which entailed delivery of HD either at home or in a long-term care facility. Although there was considerable geographic variability, out-of-center HD was the initial treatment modality for less than $1 \%$ of patients initiating dialysis in the US during the study

Nephron Clin Pract 2010;116:c53-c59 
period. PD was also an infrequent modality with only $8 \%$ of patients initiating dialysis. We found that a similar relative risk of death between the PD patient and out-of center patients. In contrast to previous studies $[3,5,10,13$, 14], we found no consistent association between out-ofcenter HD and better patient survival as compared with in-center HD. In fact, the relative risk of death among patients initiating out-of-center HD was significantly higher compared to those initiated on in-center HD. However, the relative risk of death associated with out-ofcenter HD was lower than for in-center HD when only younger, healthier patients were considered, and arguably might represent the true home HD patient population.

\section{Previous Literature}

Much of the existing literature on out-of-center HD is focused on home HD, and is based on small single-center studies of prevalent patients from 1980 to 1990 that (in contrast to our findings) generally observed that home $\mathrm{HD}$ is associated with better outcomes. These studies may not reflect current practice patterns, and may be prone to selection bias. Other analyses of home HD based on USRDS data have led to different findings. Woods et al. [10] studied a smaller, random sample of 4,892 Medicare-entitled incident ESRD patients who initiated dialysis between 1986 and 1987 and were included in a special USRDS study of case mix severity. The 70 home HD patients identified in that study were younger, had fewer comorbid conditions and had a lower adjusted risk of death compared to those receiving in-center HD. In contrast, the 1,641 unselected contemporary incident out-ofcenter HD patients included in our study had a higher frequency of comorbid conditions such as IHD and CHF, and were less likely to ambulate or transfer independently than patients treated with other dialysis modalities. Although our study included a larger group of unselected patients initiating out-of-center $\mathrm{HD}$, the potential growth of HD delivery in long-term care facilities might have confounded our results, compared to the previously reported USRDS analysis.

\section{Study Limitations}

Our analysis has several limitations that should be considered when interpreting the results. First, although we adjusted for measured comorbidity and other patient characteristics (including the propensity to be treated with out-of-center HD), assignment to a particular dialysis modality was not randomized and therefore the possibility of residual confounding remains. Second, al- though this is the largest cohort of incident out-of-center HD patients studied to date, we included only those with Medicare as a primary payer in the US, and therefore our findings may not be applicable to other populations. Third, our analysis includes all patients who initiated dialysis over a 10 -year period. Since there have been advances in home HD technologies and changes in the structure of typical home HD programs during this period, our findings may not fully reflect outcomes among home HD patients today. Fourth, we did not have information on the duration, frequency, or dose of dialysis among patients receiving home $\mathrm{HD}$, and thus we were unable to examine survival among patients who were prescribed long nocturnal, short daily or other home HD prescriptions. Similarly, we were not able to determine whether patients received nurse-assisted or self-care dialysis at home. Fifth, despite the fact that infections related to vascular access is an important determinant of mortality, this outcome was not captured in the dataset and could not be explored.

Most importantly, the definition of out-of-center HD that we used included patients who were treated at home or in long-term care facilities. Since the latter patients would likely be less healthy than those living at home, this might have led to a spuriously increased risk of mortality in the out-of-center HD population. Although we attempted to adjust for factors that might be associated with residence in a long-term care facility, some residual confounding appears likely. However, the lack of an overall association between out-of-center HD and better survival, and the interaction between age and comorbidity on the relative risk of death associated with out-of-center HD suggest that selection bias may have influenced the findings of prior studies that have evaluated outcomes among patients receiving $\mathrm{HD}$ at home. These findings support the need for establishing daily/more frequent home HD registries such as the recently established International Quotidian Dialysis Registry [20,21], in an effort to better characterize the use and outcomes of patients receiving $\mathrm{HD}$ at home compared to other modalities.

\section{Conclusion}

Out-of-center HD does not appear to be associated with a survival advantage among an unselected incident ESRD patient population initiating dialysis in the US. Our findings highlight the potential importance of prospective national registries and large randomized con- 
trolled trials that compare the use, outcomes and benefits of home and more frequent HD to those associated with standard therapies. Efforts are already under way to further characterize the potential short- and long-term benefits of home HD, including the 2 ongoing Frequent Hemodialysis Network trials $[18,22]$ and a recently completed randomized controlled trial. In addition, the International Quotidian Dialysis Registry [20] and ongoing cohort studies of home HD [23] will further shed light on this resurging therapy.

\section{Acknowledgements}

The data reported here have been supplied by the United States Renal Data System (USRDS). The interpretation and reporting of these data are the responsibility of the authors and in no way should be seen as official policy or interpretation of the US government. J.S.G. is supported by the Michael Smith Foundation for Health Research. C.L.R. is supported in part by the Canadian Institutes for Health Research. B.L.J. is supported in part by a grant from the National Institutes of Health (DK077751). The statistical analyses were performed by J.S.G. and C.L.R. who take responsibility for the accuracy of the analyses. The authors wish to acknowledge the tremendous support of Allan J. Collins, MD, and Cheryl Arko from the USRDS for their support in preparing this analysis.

\section{References}

1 Shaldon S: Origin of home haemodialysis. Nephrol Dial Transplant 2006;21:3610-3611.

2 Blagg CR: Home haemodialysis: 'home, home, sweet, sweet home!'. Nephrology 2005; 10:206-214.

-3 Saner E, Nitsch D, Descoeudres C, Frey FJ, Uehlinger DE: Outcome of home haemodialysis patients: a case-cohort study. Nephrol Dial Transplant 2005;20:604-610.

-4 Nesrallah GE, Moist LM, Awaraji C, Lindsay RM: An international registry to compare quotidian dialysis regimens with conventional thrice-weekly hemodialysis: why, how and potential pitfalls. Semin Dial 2004;17: 131-135.

5 Kjellstrand CM, Buoncristiani U, Ting G, Traeger J, Piccoli GB, Sibai-Galland R, Young BA, Blagg CR: Short daily haemodialysis: survival in 415 patients treated for 1006 patient-years. Nephrol Dial Transplant 2008;23:3283-3289.

-6 Blagg CR: The renaissance of home hemodialysis: where we are, why we got here, what is happening in the United States and elsewhere. Hemodial Int 2008;12:S2-S5.

7 Ganesh SK, Hulbert-Shearon T, Port FK, Eagle K, Stack AG: Mortality differences by dialysis modality among incident ESRD patients with and without coronary artery disease. J Am Soc Nephrol 2003; 14:415-424.

-8 Mohr PE, Neumann PJ, Franco SJ, Marainen J, Lockridge R, Ting G: The case for daily dialysis: its impact on costs and quality of life. Am J Kidney Dis 2001;37:777.

19 Pierratos A: Daily nocturnal home hemodialysis. Kidney Int 2004;65:1975.
10 Woods J, Port FK, Stannard D, Blagg CR, Held PJ: Comparison of mortality with home hemodialysis and centre hemodialysis: a national study. Kidney Int 1996;49:1464-1470.

11 Evans R, Manninen DL, Garrison LP Jr, Hart LG, Blagg CR, Guttman RA, Hull AR, Lowrie $\mathrm{E}$ : The quality of life of patients with endstage renal disease. N Engl J Med 1985;312: 553-559.

12 Bremer BA, McCauley CR, Wrona RM, Johnson JP: Quality of life in end-stage renal disease: a re-examination. Am J Kidney Dis 1989;13:200-209.

-13 Mailloux LU, Kapikian N, Napolitano B, Mossey RT, Bellucci AG, Wilkes BM, Vernace MA, Miller IJ: Home hemodialysis: patient outcomes during a 24 -year period of time from 1970 through 1993. Adv Ren Replace Ther 1996;3:112-119.

14 Grant AC, Rodger RS, Howie CA, Junor BJ, Briggs JD, Macdougall AI: Dialysis at home in the west of Scotland: a comparison of hemodialysis and continuous ambulatory peritoneal dialysis in age- and sex-matched controls. Perit Dial Int 1992;12:365-368.

15 Agar JW, Knight RJ, Simmonds RE, Boddington JM, Waldron CM, Somerville CA Nocturnal haemodialysis: an Australian cost comparison with conventional satellite haemodialysis. Nephrology 2005;10:557-570.

16 Mowatt G, Vale L, MacLeod A: Systematic review of the effectiveness of home versus hospital or satellite unit hemodialysis for people with end-stage renal failure. Int $\mathrm{J}$ Technol Assess Health Care 2004;20:258268.

17 Blagg CR: A brief history of home hemodialysis. Adv Ren Replace Ther 1996;3:99-105.
18 Culleton BF, Walsh M, Klarenbach SW, Mortis G, Scott-Douglas N, Quinn RR, Tonelli M, Donnelly S, Friedrich MG, Kumar A, Mahallati H, Hemmelgarn BR, Manns BJ: Effect of frequent nocturnal hemodialysis vs. conventional hemodialysis on left ventricular mass and quality of life: a randomized controlled trial. JAMA 2007;298:1291-1299.

19 US Renal Data System: Patient characteristics at the start of ESRD: data from the HCFA medical evidence form. Am J Kidney Dis 1999;34:S63-S73

20 Nesrallah GE, Suri RS, Moist LM, Cuerden M, Groeneweg KE, Hakim R, Ofsthun NJ, McDonald SP, Hawley C, Caskey FJ, Couchoud C, Awaraji C, Lindsay RM: International Quotidian Dialysis Registry: annual report 2009. Hemodial Int 2009;13:240249.

21 Nesrallah GE, Suri RS, Moist LM, Ofsthun NJ, Hakim R, McDonald SP, Marshall MR, Carter ST, Lindsay RM: The International Quotidian Dialysis Registry: annual report 2008. Hemodial Int 2008; 12:281-289.

-22 Suri RS, Garg AX, Chertow GM, Levin NW, Rocco MV, Greene T, Beck GJ, Gassman JJ, Eggers PW, Star RA, Ornt DB, Kliger AS: Frequent Hemodialysis Network (FHN) randomized trials: study design. Kidney Int 2006;71:349.

23 Jaber BL, Finkelstein FO, Glickman JD, Hull AR, Kraus MA, Leypoldt JK, Liu J, Gilbertson D, McCarthy J, Miller BW, Moran J, Collins AJ, FREEDOM Study Group: Scope and design of the Following Rehabilitation, Economics and Everyday-Dialysis Outcome Measurements (FREEDOM) Study. Am J Kidney Dis 2009;53:310. 